\title{
FRAGMENTI IZ CRKVENE I SVJETOVNE POVIJESTI PODGORJA U 19. I 20. STOLJEĆU
}

\author{
Željko Holjevac \\ Sveučilište u Zagrebu \\ Filozofski fakultet \\ Ivana Lučića 3 \\ HR 10000 Zagreb \\ zholjeva@ffzg.hr
}

\author{
UDK: 27(497.5 Podgorje)(091) \\ 94(497.5 Podgorje) \\ Izvorni znanstveni članak \\ Ur.: 2017-04-30
}

Na temelju raspoloživih izvora i odabrane literature autor donosi neke podatke i spoznaje o nedovoljno istraženoj crkvenoj i svjetovnoj prošlosti Podgorja u modernom i suvremenom razdoblju. Podgorje je do razvojačenja 1873. i povratka Vojne krajine pod bansku vlast 1881. bilo podijeljeno između Smiljanske satnije u Ličkoj i Svetojurjevske satnije u Otočkoj pukovniji,. Samo je Karlobag bio vojni komunitet, kaštelanat i slobodna luka. Od 1809. do 1813. bilo je Podgorje pod francuskom upravom u sklopu Vojne Hrvatske kao dijela Ilirskih pokrajina, a zatim opet pod austrijskom (habsburškom) upravom. Domaći ljudi bili su Hrvati, uglavnom katolici i štokavci. Bili su to siromašni seljaci koji su u doba Vojne krajine obavljali i vojnu službu. Bavili su se obradom škrte zemlje, uzgojem stoke na velebitskim obroncima, izradom odjeće i opanaka, sječom stabala za jarbole, ribarenjem, prosjačenjem i rijetko kakvim obrtom. Žitelji uz more odijevali su se "po gradsku", a oni u planini "po bunjevačku", kako su 1850. pisali podgorski župnici. Između dvaju svjetskih ratova većina je Podgoraca još živjela ustaljenim pastoralnim životom prema obrascima koji su se prenosili s koljena na koljeno. Uvijek u nuždi, više gladni nego siti, oskudijevali su pitkom vodom, npr. u Cesarici, gdje je 1937. na tisuću stanovnika dolazila jedna šterna. Razvojno zaostajanje Podgorja za vrijeme monarhističke Jugoslavije nastavilo se poslije kušnji tijekom Drugoga svjetskog rata kroz dugo stajanje u mjestu za vrijeme socijalističke Jugoslavije. Dovršetak izgradnje Jadranske magistrale 1965. olakšao je razvoj turizma, osobito u Karlobagu koji je dobio motel i trajektno pristanište, ali su taj razvoj ometali nedostatak pitke vode, bacanje smeća u more, divlja gradnja objekata i drugi problemi. Istodobno je politički život bio pod partijskim monopolom, Katolička crkva odvojena od države i društveno marginalizirana, a iseljavanje ljudi i pad nataliteta poprimili su kataklizmičke razmjere. U takvim prilikama Podgorje je dočekalo Domovinski rat i državno osamostaljenje Republike Hrvatske.

Ključne riječi: Podgorje, Katolička crkva, narodni život, 19. st., 20. st. 


\section{Uvod}

Podgorje je prije razvojačenja 1873. i povratka Hrvatsko-slavonske Vojne krajine pod bansku vlast 1881. živjelo pod vojnom upravom. Bilo je podijeljeno između Smiljanske satnije u sastavu Ličke pukovnije sa središtem u Gospiću i Svetojurjevske satnije u sastavu Otočke pukovnije. Prva je obuhvaćala južni, a druga sjeverni dio Podgorja. Sveti Juraj bio je jedino podgorsko mjesto koje je ujedno bilo satnijsko središte, a samo je podvelebitski lučki gradić Karlobag bio vojni komunitet (gradska općina), kaštelanat i slobodna luka. ${ }^{1}$ Pored starih katoličkih župa (Jablanac, Karlobag, Sveti Juraj) i samostana kapucina s crkvom sv. Josipa u Karlobagu, na prijedlog senjskog i modruškog ili krbavskog biskupa Ivana Krstitelja Ježića donijelo je Ugarsko namjesničko vijeće na Budimu 1807. odluku o osnivanju šest novih župa u Podgorju: Cesarica, Krasno, Lukovo Otočko, Lukovo Šugarje, Prizna i Starigrad. ${ }^{2}$ Od tada su se vikari i kapelani u tim mjestima potpisivali kao župnici. Od 1809. do 1813. nalazilo se Podgorje pod francuskom upravom u sklopu Vojne Hrvatske kao dijela Ilirskih pokrajina u sastavu Francuskoga Carstva. Pod obnovljenom austrijskom upravom, poslije vojničkog i političkog sloma Napoleona, osnovana je Primorska gubernija sa sjedištem u Trstu. Pod njezinu upravu stavljene su 1815. morske luke u Senju i Karlobagu, zajedno sa sanitarnim uredima u Svetom Jurju i Jablancu. ${ }^{3}$

\section{Svjetovne i crkvene prilike u prvoj polovici 19. stoljeća}

Franjo Julije Fras piše da je Smiljanska satnija 1830. obuhvaćala naselja Konjsko, Ledenik, Kućište, Stanište i Cesaricu. Istodobno je Svetojurjevska satnija obuhvaćala naselja Sv. Juraj, Jablanac, Stinicu, Priznu, Kladu, Lukovo Otočko, Volarice, Biljevine, Stolac, Dragu i Krasno. U Svetom Jurju je 1799. otvorena trivijalna škola s njemačkim, dok je u Krasnu radila pučka škola s hrvatskim kao nastavnim jezikom, ali je siromašni narod teško uzdržavao učitelje. I u Jablancu je 1828. otvorena pučka škola, ali je već 1832. premještena u Sinac. U Karlobagu se ranije nalazila glavna škola, a od 1833. samo trivijalna. ${ }^{4}$ Taj se podvelebitski gradić sporo oporavljao od posljedica

\footnotetext{
${ }^{1}$ F. de P. J. FRAS, 1988, 255.

${ }^{2}$ M. BOGOVIĆ, 2003, 43.

${ }^{3}$ Hrvatski državni arhiv (dalje: HDA), Zagreb, Ujedinjena bansko-varaždinsko-karlovačka generalkomanda, kut. 33 .

${ }^{4}$ F. de P. J. FRAS, 1988, 158, 186-188, 258.
} 
napada engleske fregate koja je 1813. otvorila topovsku paljbu na tamošnju utvrdu u kojoj se nalazila francuska posada. Iako je ostao komunitetom, kaštelanatom i slobodnom lukom, u koju su od druge polovice 19. stoljeća uplovljavali i manji parobrodi, Karlobag je doživio ograničen gospodarski i društveni polet, ostajući čvrsto u sudbinskome zagrljaju oskudnoga krajolika. Zbog toga je 1871. izgubio komunitetske povlastice i ostao tek slobodni lučki grad, a kasnije je bio samo središtem jedne od političkih općina u sastavu kotara Gospić.

U Jablancu je 1799. sagrađena crkva koju je 1. srpnja iste godine posvetio senjski i modruški ili krbavski biskup Ivan Krstitelj Ježić. Karlobažanin Šime Dadić, koji je od 1834. do 1877. bio župnik u Lukovu Šugarju, sagradio je 1836. crkvu i župni stan u tome mjestu. U Cesarici je 1841. napušten župni stan zbog trošnosti pa su mjesni dušobrižnici do 1852. morali stanovati u Karlobagu, a župljani su po zapovijedi Smiljanske satnije morali na vlastiti trošak dovoziti i odvoziti dušobrižnike. Cesarička župna nadarbina sastojala se od jednog i pol rala zemljišta u Novom u Lici (danas Lički Novi). Međusobnim sporazumom o uživanju tog zemljišta bilo je uređeno da $1 / 4$ pripada župniku u Novom uz uvjet da nadzire zemljište, a $3 / 4$ dušobrižniku u Cesarici. U spomenici cesaričke župe zabilježeno je da su 23 čovjeka morala 1845. davati župniku jedan voz ili četiri tovara drva. Kasnije su župljani počeli oskudijevati u drvima pa su davali župniku manju odštetu u novcu. Crkva sv. Luke u Lukovu Otočkom sazidana je 1843. troškom Svetojurjevske satnije i Otočke pukovnije. U Svetom Jurju je crkva sv. Filipa i Jakova na mjesnom groblju bila župna crkva prije nego što je 29. ožujka 1845. napuštena. Poslije toga se služba Božja obavljala u crkvi sv. Jurja. Ta je crkva pukla 1852., pa se sveta misa služila u jednom vojničkom skladišu dok 1856. nije sazidana nova župna crkva, koju je četiri godine kasnije posvetio senjski i modruški ili krbavski biskup Vjenceslav Soić. ${ }^{5}$

\section{Narodni život i gospodarstvo sredinom 19. stoljeća}

Domaći ljudi u Podgorju bili su gotovo isključivo Hrvati, uglavnom katolici i štokavci. Gdjekoji su govorili "ca", a gdjekoji "sto" umjesto "što". Bili su to siromašni seljaci koji su u doba Vojne krajine obavljali i vojnu službu. Muškarci su se bavili obradom škrte zemlje, uzgojem stoke na velebitskim obroncima, izradom prtene i suknene odjeće i prostih opanaka, sječom stabala za jarbole, brodarenjem, ribarenjem, prosjačenjem i rijetko kakvim obrtom. Žene

\footnotetext{
${ }^{5}$ Biskupski arhiv, Senj (dalje: BAS), Podaci župa, 1925.
} 
su se uglavnom bavile šivanjem, predenjem, tkanjem i pletenjem za potrebe vlastitih domaćinstava. Obrtnika je bilo malo, a među njima je najviše bilo onih koji su svojim radom zadovoljavali skromne potrebe svojih sumještana poput samoukih kovača, kolara, škrinjara, kalafata, čizmara, zdjelara, žličara, bačvara i drvodjelaca. Svatko je znao izraditi opanke ili stolicu na tri ili četiri nožice. Mnogi Podgorci bili su dobri mornari, kramari i presličari. Žitelji uz more odijevali su se "po gradsku", a oni u planini "po bunjevačku", kako su 1850. pisali podgorski župnici. "Nošnja naroda Svetoga Jurja nerazlikuje se po vjerozakonu koliko muško toliko žensko nosi se po gradsku, koji može od skuna kupovnoga od stacuna kupi i nosi kratku halju, pantalone, persluk, kapu cernu ili klobuk mornarski, gje koji po cipele, čizme i to malo, i opanke, i stoga se zovedu seljani od imenoa rodnoga Svetojurčani. Ovi svi planinari zovu se Bunjevci, svi rekoh od ostalih na drugoj strani upisatih mjesta, i ovi se svi u nošnji po vjerozakonu razlikuju. Muški nose bjele ili merke breveneke, haljince cerne ili merke, cerljene Rakčine, ili klobuke široke niske, kapica ili nazubke s natikačam i svaki opanke. Žene njihove nose sadak cerni brez rukavi, haljinu cernu s rukavi, kapicu za pasom, bičve na nogam i opanke, jačmak po svoj glavi nosidu povezat, vlasi ispred ušiu podugačko vise, $i$ to spletene kao rišćanke. Cure nosidu na glavi niski cerveni rakčin i po polovici rakčina pripućen jačmak s bačenkom. Odiću ostalu nose kako i žene, cure samo na nogam nose čarape mesto bičavah i opanke.", napisao je 11. svibnja 1850. župnik Ambroz Krišković u Svetom Jurju. ${ }^{6}$

Poljski proizvodi bili su neznatni jer u kamenitim, pjeskovitim i zimovitim stranama nista drugo nije raslo nego pir, zob, ječam, ponešto pšenice i krumpira. Ječma je i najrodnijih godina bilo jedva za trećinu godine, a mnogo puta nije se dobivala ni polovica sjemena. Uz more u Starigradu i na velebitskoj primorskoj padini narod je krčio kamenito tlo i s velikom mukom sadio lozu, smokvu, breskvu, marelicu i badem. Zbog pomanjkanja kvalitetne zemlje uzgajalo se malo krumpira, a kupusa je u pojedinim dolinama za obilnih godina bilo dovoljno samo za četvrt godine pa je narod za taj proizvod morao potezati u Karlobag ili Senj. Domaći je seljak najviše živio od ribe i stoke, uzgajajući nešto krava i volova. Konja je bilo tu i tamo, a jedino se mula moglo vidjeti u nešto većoj množini, dok je magaraca, koza i ovaca bilo znatno manje. Bukovine, jelovine i smrekovine na Velebitu bilo je u izobilju pa je to uzdržavalo narod. Zimi su ljudi boravili kod mora, a ljeti izlazili u

${ }^{6}$ Hrvatski povijesni muzej (dalje: HPM), Zagreb, Dokumentarna zbirka, Inv. br. 20.852. 
velebitske stanove. U kamenitom primorskom krajoliku nije bilo vode, osim mora i malobrojnih šterni u kojima se moglo skupiti nešto kišnice s krovova. U Krasnu su stanovnici bili prisiljeni svake godine po ljetnoj žegi ići pješice po vodu u četiri sata hoda udaljenu Švicu ili Kosinj. Iznad mjesta Jablanca nalazila se živa voda na jednom brdu, a duž morske obale i u samom moru bilo je više izvora pitke vode. Živi Bunari u okolici rijetko kada su presušivali, iako je u Podgorju bilo mnogo zapuštenih bunara od starine. Dvadesetak koraka od župnog stana u Starigradu izvirala je 1850. živa voda koja se u lipnju, srpnju i kolovozu zaslanjivala, dok je u ostalim mjesecima bila pitka i zdrava. Istodobno se u Svetom Jurju kraj mora nalazio bunar u kojem je samo za vrijeme velikih vrulja u moru bilo vode koja bi u njemu ostala dva dana slana, a zatim bi opet postala slatka. Za potrebe puka i stoke bilo je na Velebitu više snježnica, iz kojih se snijeg mnogo puta vadio, nosio prema stanovima i topio u koritima. Veliki broj jarbola za brodove, tanjih i debljih, spuštao se svake godine pomoću ljudskih mišića i čvrstih konopa do državnih skladišta za drvo na morskoj obali, odakle su se izvozili u inozemstvo. ${ }^{7}$

\section{Katolička crkva u Podgorju u drugoj polovici 19. i prvoj polovici 20. stoljeća}

Novčanom potporom dobivenom od Ministarstva rata u Beču podignut je 1869. župni stan u Karlobagu. Kraljevskim otpisom 1871. ustanovljena je svećenstvu u duhovnoj pastvi bivše Vojne krajine godišnja plaća u iznosu od kasnijih 1000 kruna, a uz to stan u naravi i drva za ogrijev. Zbog velikog siromaštva pučanstva upućivala se svake godine molba vlastima da umjesto drva doznače novčanu odštetu. Papa Pio IX. nadario je 1876. kapelu Majke Božje u Krasnu s "indulgentiis plenariis". U Starigradu je 1891. porušena stara crkva na groblju, a pet godina kasnije sagrađena je nova crkva. Ona nije posvećena, nego samo blagoslovljena. U Kladi je još 1897. sagrađena kapela sv. Nikole, koja je blagoslovljena tri godine kasnije, a u Brisnicama je deset godina kasnije sagrađena i blagoslovljena kapela u čast Presvetoga Srca Isusova. Na molbu župnika i župljana u Jablancu, zemaljska vlada u Zagrebu promijenila je 1907. podavanja u naturi u otkup u novcu. ${ }^{8}$ 20.852.

${ }^{7}$ Hrvatski povijesni muzej (dalje: HPM), Zagreb, Dokumentarna zbirka, Inv. br. 20.277 -

${ }^{8}$ BAS, Podaci župa, 1925. 
Prije i poslije Prvoga svjetskog rata župom Lukovo Šugarje upravljali su kapucini iz Karlobaga. Oko zavjetne kapele Majke Božje u Krasnu okupljao se svake godine veliki broj ljudi za Veliku i Malu Gospu. Istodobno je na veliko proštenje na blagdan Sv. Ivana Krstitelja u Prizni mnogo naroda dolazilo i sa susjednih otoka. U župi je postojala kapela sv. Antuna Padovanskog, a crkva je posjedovala dva mala vrta veličine $1 / 4$ jutra. Podavanja su se svodila na četiri tovara drva, ukupno jedan kubni metar, odnosno odštetu u novcu kao u svim župama bivše Vojne krajine. U župu je dolazilo nekoliko komada Glasnika Srca Isusova, jednog od najstarijih vjerskih časopisa koji izlazi i danas. Gornjoj Kladi je 1927. sagrađena kapela Majke Božje Lurdske. U Brisnicama je 1926. osnovano groblje i otvorena osnovna škola. I u Gornjoj Kladi je 1929. otvorena osnovna škola, dok je u Gornjem Starigradu godinu dana kasnije osnovano groblje. U Karlobagu je još 1923. pokrenut čipkarski tečaj, ali je zbog pomanjkanja polaznika preseljen na Krk. Tih godina osnovane su ribarske zadruge u Starigradu i Donjoj Kladi i pčelarske zadruge u Donjoj Kladi i Brisnicama, a utemeljena je i voćarska zadruga za starigradsku župu. U Starigradu je postojalo društvo Srca Isusova, misne zadruge i ženski crkveni pjevački zbor, a župljani su podavali župniku drvarinu. U župu je dolazilo 26 komada Glasnika Srca Isusova i 20 komada Sv. Josipa. U starigradskoj župi bilo je 36 članova Društva sv. Jeronima. U Jablancu je crkva posjedovala vrt veličine $1 / 4$ jutra, župni stan i jednokatnu kuću, ostavštinu Marije Dragičević. Lukno se sastojalo od podavanja četvornog metra drva za ogrijev po kućnom broju, a novac se podavao prema prilikama. Općinski odbor je 30. listopada 1924. zaključio da svaki dom od početka sljedeće godine daje 15 dinara. U župu je dolazilo 30 komada Glasnika presvetog Srca Isusova. ${ }^{9}$

U župi Karlobag nalazile su se ruševine filijalnih crkava sv. Nikole i sv. Vida. U toj je župi postojala bratovština Sv. Sakramenta i bratovština "animarum in purgatorio sub patrocinio B.M.V.", ali je ova druga bila kratka vijeka. Kod kapucina je postojao Treći red i Bratovština Presvetoga srca Isusova, a od 1937. spominju se Treći red sv. Franje i Društvo S.I. Župna crkva u Krasnu posjedovala je stan i zemljište veličine 2547 četvornih hvati, a kapela Majke Božje stan i kolibu od 180 četvornih hvati. Prostor oko kapele obuhvaćao je šest rali i 1423 četvorna hvata. Ukupno je veličina crkvenih zemljišta, što livada što oranica, iznosila 2875 četvornih hvati. Svaki kućni broj u Krasnu davao je župniku voz drva i balu sijena. U župi su 1937. postojala sljedeća društva: Mali

${ }^{9}$ BAS, Podaci župa, 1925. 
križari, Male križarice, Apostolat molitve za muževe i žene i Djevojačko S.I. U župu je dolazilo pet komada Glasnika presvetog Srca Isusova, dva komada $S$. Ante i pet komada Sv. Josipa. U Lukovu je crkva posjedovala 1/4 rali zemljišta, lukno se svodilo na drvarinu, a u župu su dolazili Glasnik Srca Isusova i $S v$. Josipa te Knjiga društva sv. Jeronima. U Svetom Jurju nalazile su se kapele sv. Ivana i sv. Nikole. Jedna pučka škola postojala je u samome mjestu, a druga na Oltarima, čak 12 i pol kilometara udaljena od mjesta. Župna nadarbina sastojala se u godišnjoj plaći. Zemljišnih posjeda nije bilo, osim dva mala vrta oko župnoga stana površine 135 četvornih metara. Podavanja su se svodila na 1/6 hvati drva od svakoga kućnog broja. U Svetom Jurju je djelovalo društvo Srca Isusova, a uz njega i Jugoslavenski sokol "sa par članova". U župu je dolazilo 15 komada Glasnika Srca Isusova i pet komada Glasnika Sv. Ante te glasila Vrhbosna i Katolički list. ${ }^{10}$

\section{Gospodarska i socijalna trajanja i promjene u tijeku 20. stoljeća}

Između dvaju svjetskih ratova većina je Podgoraca još živjela ustaljenim pastoralnim životom prema obrascima koji su se prenosili $\mathrm{s}$ koljena na koljeno. Nakon što su osnovane ribarske zadruge u Starigradu i Donjoj Kladi, a pčelarske zadruge zaživjele u Donjoj Kladi i Brisnicama, i u Lukovu Otočkom osnovana je 1931. ribarska zadruga. Uvijek u nuždi, više gladni nego siti, Podgorci su naročito oskudijevali pitkom vodom, npr. u Cesarici, gdje je 1937. na tisuću stanovnika dolazila jedva jedna šterna. "Glavni je problem u životu Podgoraca voda. Za vodu se pate i u Podgorju i na Velebitu. Poznata je stvar da je primorska strana Velebita vrlo siromašna živim vodama, pa se narod u najviše slučajeva služi cisternama, kamenicama i manjim izvorima žive vode u području brjegova; važno sredstvo za namirenje vode predstavljaju i 'sniježnice', tj. duboke kraške jame, u kojima se snijeg sadrži do kasno u ljeto, a ima i takvih u kojima se snijeg nikada potpuno ne otopi. Kamenice su slične sniježnicama, samo je ta razlika, da su od prirode izdubene u nepropusnom kamenu te se snijeg otopi i voda zadrži, odatle je onda crpu stanari. Oko svakog stana ili 'varoši' (kako nazivaju veće stanove) nalazi se po nekoliko kamenica, koje su često i privatno vlasništvo jedne porodice pa stoje pod ključem. Naime ima i umjetnih kamenica, tj. da stanari oveću jamu, na kojoj se nalaze brojne pukotine obziđu cementom, pa u proljeću u nju natrpaju snijega, koji se otopi, te ga ljeti rabe kao vodu", napisao je tih

${ }^{10}$ BAS, Podaci župa, 1925. 
godina dr. Ivan Šmalcelj. ${ }^{11}$ Karlobažani nastanjeni u Zagrebu posjetili su 1937. ministra građevina koji je obećao da će se uskoro početi graditi vodovod za Karlobag. Za tu svrhu odobren je i prvi kredit u iznosu od 600.000 dinara. ${ }^{12}$ Karlobag je u to vrijeme bio jedno od najugodnijih i najjeftinijih ljetovališta u ličkom primorju, a najljepši izleti bili su oni morem duž Velebita, ali je lička rivijera bila posve zapuštena i zapostavljena. Sve se više uviđala važnost zamišljenog cestovnoga tunela ispod Velebita, a primorski pojas od Senja do Obrovca trebao je i vlastito parobrodarsko društvo kakvo je postojalo u doba Austro-Ugarske, naime Hrvatsko parobrodarsko družtvo u Senju.

Ipak se strukturno nazadovanje Podgorja, zapaženo za monarhističke Jugoslavije, nastavilo i poslije teških kušnji i lomova u Drugom svjetskom ratu i poraću, čije su razorne posljedice, prije svega ljudske žrtve i materijalne štete, bile velike i dugo su se osjećale. Daljnje zaostajanje podgorskoga kraja u razvoju očitovalo se kroz dugotrajno stajanje u mjestu, unatoč nekim iskoracima za socijalističke Jugoslavije.

Dovršetak izgradnje Jadranske magistrale 1965. olakšao je razvoj turizma, osobito u Karlobagu koji je još 1963. dobio motel, a 1969. uređeno je ondje i novo trajektno pristanište. Napomenuti treba da je dionica Jadranske magistrale u Karlobagu izgrađena preko dijelova crkve sv. Karla Boromejskog, oštećene razaranjima u Drugom svjetskom ratu. Karlobažani su na referendumu 1966. glasovali za odcjepljenje od općine Gospić i pripajanje općini Senj. Očekivalo se da će senjska općinska skupština raspisati referendum za pripajanje karlobaškog područja, ali je Karlobag odlukom Republičkog vijeća Sabora 1967. ipak ostao u općini Gospić. Modernizacijom ceste GospićKarlobag 1968. donekle je oživjela zapuštena lička rivijera, ali je bilo i sve više prometnih nezgoda jer je više od 10.000 vozila dnevno prolazilo kroz Karlobag, a materijalne štete na podgorskim zavojima Jadranske magistrale brojile su se u milijunima. Veliku smetnju daljnjem razvoju turizma na ličkoj rivijeri činio je kroničan nedostatak pitke vode. Karlobag je 1975. bio žedan, imao je i manje noćenja nego prethodne godine, a bacanje smeća u more zagađivalo je okolicu i posebno pitku vodu. Na jednoj od sjednica izvršnog vijeća u Gospiću razmatrano je 1975. izvješće o divljoj gradnji objekata uz Jadransku magistralu na području mjesne zajednice Karlobag, u kojoj se mladi ni u ljetno doba nisu imali gdje zabaviti, a u zimskom razdoblju pogotovo.

${ }^{11}$ R. BIĆANIĆ - Ž. MACAN, 1939, 58-59.

${ }^{12}$ Lička sloga, 6/IV, Zagreb, 2. ožujka 1937. 
Katastrofalna suša 1985. pogodila je čitavu Liku, a posljedice su bile vrlo teške. U pomoć su pristigle cisterne iz mnogih gradova. Teškoće je imalo i gospodarstvo, a stoka se odgonila na velike udaljenosti kako bi je vlasnici napojili. ${ }^{13}$ U Karlobagu je motel 1978. prodan "Industrogradnji", a 1985. u mjestu je otvoren hotelski kompleks "Zagreb". U suton bivše države, 1989., kočari su haračili u podvelebitskom kanalu, utoliko lakše kad već tri godine službena tijela nisu imala čamac pomoću kojeg bi mogla učinkovito nadzirati ribolov. Istodobno se politički život i u Podgorju desetljećima nalazio pod partijskim monopolom, a Katolička crkva bila je i ondje odvojena od države i društveno marginalizirana, pa je npr. kapelica sv. Marka u Šugarju 1984. bila gotovo zaboravljena, dok su iseljavanje ljudi i pad nataliteta poprimili kataklizmičke razmjere. U takvim prilikama Podgorje je dočekalo Domovinski rat i državno osamostaljenje Republike Hrvatske.

\section{Umjesto zaključka}

Podgorje je tijekom 19. i 20. stoljeća iskusilo trajanja i promjene u rasponu od Vojne krajine do predvečerja Domovinskog rata. Katolička crkva u Podgorju imala je svoje župe u pojedinim naseljima i samostan kapucina u Karlobagu. Domaći stanovnici, gotovo isključivo Hrvati, uglavnom katolici i štokavci, živjeli su teško i oskudno, boreći se često s glađu i žeđu. Razvojno zaostajanje Podgorja tijekom promatranog razdoblja očitovalo se kroz dugo stajanje u mjestu, unatoč ograničenim modernizacijskim iskoracima.

\section{Izvori i literatura}

Biskupski arhiv, Senj, Podaci župa, 1925.

Hrvatski državni arhiv, Zagreb, Ujedinjena bansko-varaždinsko-karlovačka generalkomanda Hrvatski povijesni muzej, Zagreb, Dokumentarna zbirka

Lička sloga, Zagreb

Lički vjesnik, Gospić

Rudolf BIĆANIĆ - Željko MACAN (ur.), Kako živi narod, II. knj., Zagreb, 1939.

Mile BOGOVIĆ (prir.), Senjsko-modruška ili krbavska biskupija. Izvješća biskupâ Svetoj Stolici (1602-1919), Zagreb, 2003.

Franz de Paula Julius FRAS, Cjelovita topografija Karlovačke vojne krajine, Gospić, 1988.

${ }^{13}$ Lički vjesnik, 18 (763)/XXXIII, Gospić, 15. listopada 1985. 


\section{FRAGMENTS FROM THE ECCLESIAL AND LAY HISTORY OF PODGORJE IN THE $19^{\mathrm{TH}}$ AND $20^{\mathrm{TH}}$ CENTURIES}

\section{Summary}

On the basis of available sources and selected literature, the author presents some information and insights about the insufficiently researched ecclesial and lay past of Podgorje in the modern and contemporary period. Until demilitarisation in 1873 and the return of the Military Frontier under the administration of the ban in 1881 Podgorje was divided between the Smiljan company in the Lika and the Sveti Juraj company in the Otok regiment. Only Karlobag was a military community, a 'castellanat' and free port. From 1809 to 1813 Podgorje was under French rule within Military Croatia as part of the Illyrian Provinces, and then again under Austrian (Habsburg) rule. The local people were Croats, mostly Catholics and speakers of Štokavian. They were poor peasants who during the Military Frontier period also served military service. They cultivated the poor land, bred cattle on the slopes of Velebit, made clothes and simple footwear, cut trees for masts, fished, begged and were rarely involved in any small business. Inhabitants along the sea dressed "po gradsku" ("in the town style"), whilst those in the hills "po bunjevačku" ("like the Bunjevci"), as Podgorje priests wrote in 1850. Between the two world wars, the majority of the people of Podgorje still lived the established pastoral life according to the ways that were passed from generation to generation. Always in need, more hungry than full, they lacked drinking water, e.g. in Cesarica in 1937 there was one well for the one thousand inhabitants. The developmental lagging behind of Podgorje during the time of the monarchical Yugoslavia continued after the ordeals of the Second World War through the stagnation of the place during socialist Yugoslavia. The completion of the construction of the Adriatic highway - the magistrale - in 1965 helped the development of tourism, particularly in Karlobag which gained a motel and ferry dock, however the lack of drinking water, the dumping of rubbish into the sea, the illegal construction of buildings and other problems hindered this development. At the same time political life was under the monopoly of the party, the Catholic Church was separate from the state and socially marginalised, and the emigration of people and the fall in the birth rate took on cataclysmic dimensions. Under such conditions Podgorje faced the Homeland War and the state independence of the Republic of Croatia.

Keywords: Podgorje, Catholic Church, people's life, $19^{\text {th }}$ century, $20^{\text {th }}$ century 